\title{
Letrōnica
}

\section{A igualdade em paradoxo: uma abordagem enunciativa}

\section{Equality in paradox: an enunciative approach}

Luiz Francisco Dias ${ }^{1}$

Universidade Federal de Minas Gerais, Faculdade de Letras. Belo Horizonte, MG, Brasil.

Thalita Nogueira de Souza ${ }^{2}$

Universidade Federal de Minas Gerais, Núcleo de Estudos da Enunciação. Belo Horizonte, MG, Brasil. Doutor em Linguística. Pesquisador do CNPQ (1) https://orcid.org/0000-0003-0819-4797

Em.

Ester

Estudos da Enunciação (ENUNCIAR) da UFMG

E-mail: nogueirathalita@outlook com
RESUMO: Este estudo realiza uma análise semântica do termo igualdade. Utilizou-se como fundamento a teoria da enunciação de linha francesa, desenvolvida no Brasil por Guimarães $(1995 ; 2002)$. A análise tomou como objeto textos jurídicos produzidos por ministros do Supremo Tribunal Federal, nos quais aparecem os usos da palavra igualdade. Os resultados da análise indicam que a significação dessa palavra não está fundamentada na relação " $A$ igual a $B$ ". Esse novo sentido está fundamentado na relação " $A$ deve ser igual a $B$ ". Assim, os ministros justificam a decisão de adotar cotas raciais nos processos de seleção para as universidades, no intuito de transformar em realidade esse novo conceito.

Palavras-chave: Enunciação; Igualdade; Formação nominal.

ABSTRACT: This study does a semantic analysis of the term equality. It was based on the French enunciation theory developed in Brazil by Guimarães $(1995 ; 2002)$. The object of the analysis was the legal texts produced by the ministers of the Supreme Court, in which uses of the word equality appear. The results of the analysis show that the meaning of this word is not based on the relationship " $A$ is equal to $B$ ". This new meaning is based on the relationship " $A$ should be equal to $B$ ". Thus, the ministers justify the decision to adopt racial quotas, in the selection processes for universities, in order to transform this new concept into reality

Keywords: Enunciation; Equality; Nominal training. 


\section{Introdução}

Crster

ste estudo produz uma abordagem linguística do termo igualdade, por meio dos fundamentos teóricos de uma semântica da enunciação. Trata-se de uma linha teórica de origem francesa, cujos principais expoentes foram E. Benveniste e O. Ducrot. No Brasil, essa perspectiva aberta pelos dois teóricos tem sido desenvolvida com matizes próprios por Guimarães (1995; 2002). A abordagem que desenvolvemos no presente artigo segue a linha de trabalho de Guimarães, embora também apresente matizes próprios na ênfase que imprimimos à análise das formas gramaticais como suporte do funcionamento dos processos enunciativos da significação.

Nessa direção, trabalhamos com três termos teóricos que operam na sustentação gramatical do conceito de enunciação como acontecimento da produção do enunciado. São eles: formação nominal, referencial histórico e pertinência enunciativa.

Após a apresentação dos conceitos fundamentais para a análise, expomos a origem e as condições de produção dos dados de análise. Trata-se de recortes dos votos escritos dos ministros do Supremo Tribunal Federal relativamente à legalidade de adoção de cotas para negros em processos seletivos em universidades. Nesses recortes, buscamos ocorrências de formações nominais constituídas com o termo igualdade.

Em seguida, desenvolvemos uma análise enunciativa dos dados com base nos conceitos de formação nominal, referencial histórico e pertinência enunciativa. Tendo em vista essa análise, elaboramos os fundamentos do sentido de igualdade que se sobressai dos enunciados do STF.

\section{Razão lógica da igualdade}

Frege (1978) inicia a sua clássica distinção entre o sentido e a referência por meio de uma reflexão instigante, bem apropriada para um lógico, com formação em matemática. No entender dele, a relação de igualdade constituída entre $a$ e $a$, do tipo $a=a$, difere da mesma relação constituída entre $a$ e $b$, do tipo $a=b$. A primeira sustenta-se a priori, isto é, não depende dos termos em que é enunciada para que a relação seja verdadeira. Nesse caso, estaríamos expressando a relação de igualdade absoluta ao dizer que uma coisa é igual a si mesma, concebível na concepção mais abstrata possível. Sendo assim, essa relação não contraí pertinência para a linguagem ordinária, dado que não agrega nenhum conhecimento sobre as entidades colocadas em relação. Assim sendo, a relação estabelecida entre $a$ e $a$ é sempre verdadeira.

No entanto, somos movidos a expressar em língua porque o nosso dizer releva da necessidade de se fazer pertinente, da busca e ao mesmo tempo da expressão de conhecimento, da proposição de uma verdade. Isso constituiria os fundamentos da relação entre $a$ e $b$, a qual seria uma relação asserida, no entender de Frege. Daí a compreensão de que o mundo da linguagem é permeado por relações de proposição, como em "a estrela da manhã $[a]$ é igual a estrela da tarde [b]". Essa proposição é constituída com base em um conhecimento considerado verdadeiro no âmbito da ciência, qual seja, os dois termos da relação de igualdade se referem a uma única entidade, o planeta Vênus.

Dessa maneira, em $a=b$, afirma-se uma igualdade, mas expõe-se uma diferença. Nesse caso, $a$ e $b$ não são iguais como ponto de partida. Assim, já houve um tempo em que o estado de conhecimento sobre os astros visíveis no céu não permitia a asserção de igualdade entre "estrela da manhã" e "estrela da tarde". Naquela época, "estrela da manhã" era diferente de "estrela da tarde", visto que eram consideradas estrelas, e ainda era pertinente o período do dia em que eram visíveis no céu. A relação entre $a$ e $b$ adquire pertinência justamente porque é permeada por uma relação de conhecimento da realidade. Essa relação adquire 
dependência de uma "concepção" e estaria sujeita às condições de verdade ou falsidade.

Desse modo, à apreensão de um pensamento corresponde um modo de expressá-lo, de apresentá-lo. Esse modo de expressar o que se apreende no pensamento estaria ancorado em conceitos previamente constituídos, socialmente compartilhados e aceitos por uma determinada comunidade. Um exemplo disso seria a expressão daquilo que se depreende do pensamento sobre a lua, apresentado como "satélite da terra", fruto de uma verdade consagrada na comunidade científica e que faz parte dos conhecimentos que a escola nos "faz saber".

Essa reflexão permitiu a Frege produzir os fundamentos de uma tese relativa às condições de verdade das proposições. Consideramos relevante a reflexão empreendida por Frege como introdução à sua tese. No entanto, buscamos um outro caminho, diferente da lógica de predicados, para situar a questão da significação na linguagem, tendo em vista a relação entre forma linguística, concepções de mundo e modos de expressão. Vamos abordar esse tripé através do conceito de formação nominal, no âmbito de uma teoria da enunciação.

\section{Formação nominal, referencial histórico e pertinência enunciativa}

No âmbito dos estudos morfológicos, formação nominal designa um processo de constituição de substantivos advindos de uma base verbal, como "varrer > varrição". Porém, na abordagem que temos empreendido nos últimos anos (DIAS, 2013; 2016), o fundamento do conceito de formação nominal está na constituição enunciativa do nome e na sua relação com os determinantes, formando uma unidade nominal, unidade essa convencionalmente denominada sintagma nominal. A concepção de sintagma nominal é unicamente orgânica, e aborda a estruturação das construções linguísticas com o nome e seus determinantes. A nossa concepção, diferentemente dessa, imprime uma abordagem explicativa das sequências nominais, voltada ao processo semântico da constituição da unidade nominal. Sendo assim, a abordagem enunciativa concebe as formas linguísticas pelo viés das razões de sua conformação em unidade nominal.

Dissemos anteriormente que buscamos outro caminho, diferente da lógica de predicados proposta por Frege, para abordar a relação entre forma linguística, concepções de mundo e modos de expressão. A "forma linguística" que os nominais adquirem é abordada segundo as condições enunciativas da articulação em torno da unidade nominal, como acabamos de explicar, pelo conceito de formação nominal. Por sua vez, as "concepções de mundo" são compreendidas pelo conceito de referencial histórico, e os "modos de expressão" são tomados por meio do conceito de pertinência enunciativa. Esses dois últimos conceitos propiciam o estudo do processo enunciativo da constituição da unidade nominal.

O conceito de referencial histórico tem suas raízes nas concepções de estatuto discursivo do implícito, de Achard (1999), de traços de memória, de Pêcheux (1983), e de domínio referencial, de Foucault (1986).

Achard aborda a natureza discursiva do implícito nos seguintes termos:

Do ponto de vista discursivo, o implícito trabalha então sobre a base de um imaginário que o representa como memorizado, enquanto cada discurso, ao pressupô-lo, vai fazer apelo a sua (re)construção, sob a restrição "no vazio" de que eles respeitem as formas que permitam sua inserção por paráfrase. Mas jamais podemos provar ou supor que esse implícito (re)construído tenha existido em algum lugar como discurso autônomo (ACHARD, 1999, p. 13)

Por essa concepção, o implícito não é algo "realmente-já-ouvido", mas uma anterioridade de formuláveis, concebido por ele como um imaginário, o qual colocamos em circulação nos nossos textos. 
Pêcheux, por seu lado, defende que aquilo que se enuncia sustenta materialmente os traços de uma memória de já enunciados, uma ordem de dizer diferente da materialidade orgânica do enunciado presente, configurado em unidades textualizadas. A unidades orgânicas da língua são tecidas por "já-ditos" retidos socialmente dos conflitos de regularização, próprios das tramas da história (PÊCHEUX, 1983, p. 56). Esses traços de memória são dispersos e estão sujeitos a reconfigurações permanentes. Eles seriam, na concepção de Pêcheux, "índices legíveis de tramas" constituindo um corpo sócio-histórico (PÊCHEUX, 1982, p. 286).

Por sua vez, Foucault concebe o referencial a partir da tese segundo a qual as entidades da exterioridade linguística não se encontram discriminadas e delimitadas na natureza. Elas se submetem às possibilidades históricas de emergência na enunciação. 0 compromisso de um nome não é com a entidade em si, mesmo porque ele não existiria nessa condição, mas com o campo de emergência das entidades, socialmente recortado. Sendo assim, é o próprio enunciar, e não as propriedades inerentes aos seres, estados e relações, que produz o referencial a partir do qual esses seres, estados e relações podem ser referenciados individualmente no nosso cotidiano. Os nossos enunciados se apoiam em um "suporte institucional". Para Foucault, o suporte institucional advém de tudo aquilo que escutamos, lemos, captamos ao longo da nossa vida sobre quem eu sou, quem são os outros, como os identificamos, o que são os animais, os objetos, as entidades abstratas, os extratos da natureza, e como isso tudo funciona. Esse suporte institucional se constitui de discursos, e não de um saber enciclopédico abstrato.

Por fim, o conceito de pertinência enunciativa está relacionado às demandas do presente do enunciar. As articulações que o nome contrai dentro e fora da unidade nominal são orientadas na direção dessas demandas. No cotidiano, somos instados a agir linguisticamente frente às situações enunciativas que se nos apresentam. Isso impulsiona o nosso dizer a adquirir adesão aos dizeres outros do presente. Nos termos de Dias; Zattar (2017):

0 que dizemos mantém relação com um conjunto de outros dizeres com os quais estamos em contato. Nós somos afetados por tudo aquilo que nos rodeia, seja pelo que os outros estão nos dizendo, seja pelo que estamos presenciando, seja pelo que produz alcance nos nossos sentidos, seja pelo que movimenta os nossos desejos, os nossos afetos, seja pelo que achamos que não está certo, pelo que consideramos que seja merecedor de nossa intervenção, seja pelo que achamos que devemos reforçar, elogiar, encorajar, intervir, reprimir, incentivar. E tudo isso é regulado por formas específicas de dizer, modos de se fazer reconhecer pela linguagem (DIAS; ZATTAR, 2017, no prelo).

Na constituição das formações nominais, as determinações que o nome recebe participam dessas orientações de pertinência enunciativa, tendo em vista a adesão do dizer às demandas da atualidade do dizer.

$\mathrm{Na}$ nossa perspectiva de abordagem do sentido, a enunciação é o acontecimento de produção do enunciado (GUIMARÃES, 1995; 2002). Desse ponto de vista, o enunciado adquire sentido na medida em que uma atualidade motivadora da formulação adquire pertinência na atualidade do dizer afetada constitutivamente pelos referenciais históricos evocados pela materialidade do dizer. Defendemos a tese segundo a qual a análise das formações nominais nos permite conhecer o funcionamento da enunciação, e consequentemente da constituição do sentido na linguagem. Para isso, analisamos as regularidades linguísticas da formação nominal, observando as razões enunciativas da relação entre o referencial histórico e a pertinência enunciativa do dizer. É o que veremos a seguir, na análise das formações nominais relativas ao termo igualdade. 


\section{Igualdade, cotas raciais e o apelo jurídico}

A Universidade de Brasília (UnB), no uso de sua autonomia administrativa e didático-cientifica prevista no Art. 207 da Constituição Federal de 1988, tornou-se a primeira universidade federal a aderir ao sistema de cotas raciais nos processos seletivos para captação de alunos. Através da Resolução no 38/2003, foram reservadas para o vestibular do segundo semestre de 2004, 20\% das vagas para negros (pretos e pardos) e $10 \%$ vagas para indígenas.

Entre as várias etapas do processo de seleção para a aprovação de candidatos no sistema de cotas, duas delas, a fotografia e a entrevista, para comprovar a origem racial do aluno, causaram muita polêmica nos vestibulares dos anos de 2004, 2007 e 2008. Ao prejudicar pessoas da mesma família (irmãos, irmãos gêmeos, pai e filha), o sistema de cotas da UnB ganhou grande repercussão midiática, tornando-se objeto de calorosos debates, envolvendo o meio acadêmico, o governo federal, o poder judiciário e os Movimentos Sociais Negros.

De acordo com Constituição do Brasil de 1988, é facultado aos partidos políticos com representação no Congresso propor ações de inconstitucionalidade, com base no item VIII do Art. 103 dessa Constituição. A partir da repercussão do acontecimento de implantação das cotas étnicoraciais na Universidade de Brasília-UnB, o Partido dos Democratas-DEM, protocolou, em 20 de julho de 2009, no Supremo Tribunal Federal, uma Petição Inicial ${ }^{1}$, requerendo a declaração de inconstitucionalidade do sistema de cotas da UnB, por entender que o método fundamentado no uso

\footnotetext{
${ }^{1}$ De forma geral, é um pedido escrito dirigido ao Tribunal. A Petição Inicial é o pedido para que se comece um processo. Outras petições podem ser apresentadas durante o processo para requerer o que é de interesse ou de direito das partes. No Supremo, a Petição (PET) é um processo. Disponível que <http://www.stf.jus.br/portal/glossario/verVerbete.asp?letra=A\&id=195>. Acesso em: jul. 2016.
}

do critério étnico-racial, o qual toma por base o fenótipo do vestibulando, viola vários princípios constitucionais, quais sejam:

i) Artigo 1ำ, caput (princípio republicano) e inciso III dignidade da pessoa humana; ii) Artigo 3ํㅡ, inciso IV (veda o preconceito de cor e a discriminação) ; iii) Artigo 4ํㅜ, inciso VIII (repúdio ao racismo); iv) Artigo 5o, incisos I (igualdade), II (legalidade), XXXIII (direito à informação dos órgãos públicos), XLII (combate ao racismo), e LIV (devido processo legal - princípio da proporcionalidade); v) Artigo 37, caput (princípios da legalidade, da impessoalidade, da razoabilidade, da publicidade e da moralidade corolários do princípio republicano); vi) Artigo 205 (direito universal à educação); vii) Artigo 206, caput e inciso I (igualdade nas condições de acesso ao ensino); viii) Artigo 207, caput (autonomia universitária); ix) Artigo 208, inciso V (princípio meritocrático - acesso ao ensino segundo a capacidade de cada um) (BRASIL, 2009, p. 2, grifo nosso).

Para o DEM, a adoção de cotas redundaria numa divisão desigual de direitos, visto que o Partido acredita que a exclusão/discriminação no Brasil é uma questão social e não racial. Já para a UnB e os Movimentos Sociais, a exclusão/discriminação do negro é marcada pela sua trajetória histórico-social. Nessa perspectiva, a "igualdade" significa uma participação mais igualitária da minoria socialmente vulnerável, no que diz respeito à educação superior.

Devido à relevância do tema, que toca em Princípios Fundamentais, principalmente no direito à "igualdade", um dos preceitos basilares da Lei Máxima do Estado brasileiro, o Supremo Tribunal Federal não só considerou a referida Petição (ADPF186) cabível, como também realizou uma Audiência Pública entre os dias 3 e 5 de março de 2010, na qual 38 (trinta e oito) especialistas de diversas entidades da sociedade civil e representantes dos Três Poderes debateram a utilização de critérios raciais para a reserva de vagas nas universidades públicas. O coordenador e Relator da Audiência, Ministro Ricardo Lewandowski, explicou que audiências como essas 
são convocadas quando se está em discussão na Corte temas de grande repercussão na sociedade. Além disso, a audiência teria por objetivo oferecer subsídios para o futuro julgamento da constitucionalidade desse sistema.

O resultado do julgamento configurou-se em um Acórdão, que é composto de textos como o Relatório da ADPF 186 e os votos/pareceres dos Ministros Ricardo Lewandowski (relator), Luiz Fux, Rosa Weber, Cármen Lúcia, Cezar Peluso, Gilmar Mendes e Ayres Brito (então Presidente do STF).

Para a análise, selecionamos 21 recortes da sentença do julgamento da ADPF186. Ela incide, pois, nos votos dos ministros do Supremo, especificamente, em sequencias enunciativas contendo formações nominais que integram a palavra "igualdade".

\section{A concepção de igualdade nos enunciados de ministros do STF: análise enunciativa}

A palavra "igualdade" aparece no texto do Acórdão ora sem determinação, ora acompanhada de um termo determinante. Vamos mostrar como se constroem as relações semânticas, ou seja, "as razões enunciativas da condensação de um nome ou da determinação que o nome recebe nas articulações que ele contrai no âmbito do grupo nominal" (DIAS, 2015e, p. 18).

Para implementar as análises, agrupamos formações nominais (FNs) constituídas da palavra "igualdade" em quatro grupos².

\section{a) Grupo 1}

As FNs do grupo 1 são constituídas pelo substantivo "igualdade", introduzido ou não pelo artigo definido "a". Vejamos as ocorrências desse grupo:

2 Os destaques em negrito nas ocorrências da formação nominal com "igualdade" são nossos. Todas as ocorrências constam de Brasil (2014).
(1) A igualdade, é consabido, se apresenta, na construção do constitucionalismo moderno, por dois enfoques: formal e material.

(Rosa Weber)

(2) Liberdade e igualdade constituem os valores sobre os quais está fundado o Estado constitucional

(Gilmar Mendes)

(3) Nunca houve necessidade de Constituição para proclamar a igualdade como valor de sorte a beneficiar os hegemônicos.

(Ayres Brito)

A FN “igualdade" aparece sem determinação de convergentes adjetivais ${ }^{3}$. Em Dias (2015), defendemos a tese segundo a qual o substantivo condensa ou encapsula enunciados que se direcionam para um centro a partir do qual esse substantivo adquire capacidade lexical. Nesse caso, "igualdade" condensa todo um conjunto de enunciados que apresentam $\boldsymbol{X}$ como igual a $\boldsymbol{Y}$. Esse seria o centro temático dos enunciados que sustentam o substantivo "igualdade".

\section{b) Grupo 2}

As FNs do Grupo 2 são constituídas pelo substantivo determinado por um convergente adjetival: substantivo + sintagma preposicional em $(a, d)$; substantivo + adjetivo em (b, c). Vejamos ocorrências de FNs desse grupo.

(4) É escusado dizer que o constituinte de 1988 - dada toda a evolução política, doutrinária e jurisprudencial pela qual passou esse conceito - não se restringiu apenas a proclamar solenemente, em palavras grandiloquentes, a igualdade de todos diante da lei.

(Ricardo Lewandowski)

As determinações de convergentes adjetivais são constituídas por adjetivos e por sintagmas preposionais. 
(5) A experiência demonstrou que o livre acesso à Universidade - a igualdade "na lei" - foi incapaz de promover a devida implementação do princípio da diversidade.

(Luiz Fux)

(6) A igualdade formal é a igualdade perante a lei.

(Rosa Weber)

(7) E como é difícil fazer com que ela se torne efetiva, plena e que tenhamos uma sociedade com igualdade para todos.

(Carmen Lúcia)

(8) E, sem igualdade mínima de oportunidades, não há igualdade de liberdade.

(Rosa Weber)

(9) por ser uma igualdade formal, com idêntico tratamento em normas gerais e abstratas, trata-se de igualdade presumida, enquanto desconsidera processos sociais concretos de formação de desigualdades.

(Rosa Weber)

(10) a igualação é um processo dinâmico de fazer com que aqueles que não adquiriram ainda uma condição de poder ter igualdade de oportunidades para ser igualmente livres, possam vir a adquirir essas condições.

(Carmen Lúcia)

(11) A transformação da igualdade formal, de cunho liberal clássico, em uma igualdade material, partiu de uma necessidade ética.

(Luiz Fux)

(12) No presente processo, a questão que se põe diante desta Corte Constitucional é, a rigor, a da igualdade racial.

(Rosa Weber)

(13) Terceiro ponto do meu voto é a questão da responsabilidade social e estatal de fazer com que o princípio constitucional da igualdade dinâmica, dessa igualdade que muda para transformar a sociedade e que está posta no artigo 3ํ da Constituição - que não é apenas um aviso, um conselho, mas é uma norma - que se cumpra, ou seja, que nós tenhamos políticas que cumpram o objetivo do Brasil, de fazer com que o Brasil seja uma sociedade livre, justa, solidária, com a igualdade como seu valor fundamental inscrito, como valor mesmo, desde o preâmbulo.

(Carmen Lúcia)

As FNs em análise podem ser assim distribuídas:

\begin{tabular}{|l|l|}
\hline Foco & Convergentes \\
\hline Igualdade & de todos diante da lei \\
\cline { 2 - 3 } & "na lei" \\
\cline { 2 - 3 } & perante a lei \\
\cline { 2 - 3 } & para todos \\
\cline { 2 - 3 } & mínima \\
\hline & presumida \\
\hline & de possibilidades \\
\cline { 2 - 2 } & formal \\
\hline & material \\
\cline { 2 - 2 } & racial \\
\hline & dinâmica \\
\cline { 2 - 2 } & de liberdade \\
\hline
\end{tabular}

Nessas FNs, o referencial histórico sustentador do centro temático que constitui o substantivo "igualdade" ( $X$ igual a $Y$ ) é afetado por pertinências enunciativas, materializadas nos convergentes, capazes de afetar esse referencial histórico. Essas pertinências afetam o referencial histórico de igualdade de dois modos. Parte dos convergentes materializam pertinências situantes e outros materializam pertinências deslocadoras.

De um lado, os convergentes "de todos diante da lei", "na lei”, "perante a lei", "para todos", "mínima” e "presumida” situam o referencial de igualdade. Esse modo de articulação que igualdade contrai perante os convergentes 
na FN preserva o referencial, pois apenas produz uma perspectiva de identificação, reconhecimento e muitas vezes de localização do centro temático ( $X$ igual a $Y$ ).

Por outro lado, os convergentes "de possibilidades", "formal", "material”, "racial", "dinâmica", "de liberdade" deslocam o referencial de igualdade. Nesse caso, os convergentes materializam perspectivações de diferenciação no conceito abstrato de igualdade ( $X$ igual a $Y$ ) produzindo novas "derivações" de igualdade ( $X$ igual a $Y$ em termos $Z$ ). Às vezes, a diferenciação já está explicitada nos enunciados, como igualdade formal X igualdade material, em outras vezes, a contraparte da diferenciação não está explicitada, como em igualdade dinâmica X (igualdade estática); igualdade de liberdade, igualdade de possibilidades X (igualdade contida, assentada). Nessa direção, um referencial de igualdade trazido pela memória e materializado no substantivo vai sendo transformado em função de novos embates na história, no âmbito dos espaços de enunciação da contemporaneidade. As pertinências enunciativas ancoradas nos convergentes adquirem um papel determinante nessas proposições de diferença no referencial histórico.

\section{c) Grupo 3}

No Grupo 3, ao contrário do grupo 2, a palavra "igualdade" aparece como determinante do termo que a antecede: Substantivo + sintagma preposicional. Observemos as ocorrências.

(14) O primeiro passo, para tanto, a meu sentir, consiste em revisitar o princípio da igualdade agasalhado na Lei Maior, examinando-o em seu duplo aspecto, ou seja, no sentido formal e material.

(Ricardo Lewandowski)

(15) Se, por um lado, a clássica concepção liberal de igualdade como um valor meramente formal há muito foi superada, em vista do seu potencial de ser um meio de legitimação da manutenção de iniquidades, por outro o objetivo de se garantir uma efetiva igualdade material deve sempre levar em consideração a necessidade de se respeitar os demais valores constitucionais.

(Gilmar Mendes)

(16) Com a ampla adoção de programas de cotas raciais, como ficará, do ponto de vista do direito à igualdade, a situação do "branco" pobre?

(Gilmar Mendes)

(17) A questão da constitucionalidade de ações afirmativas voltadas ao objetivo de remediar desigualdades históricas entre grupos étnicos e sociais, com o intuito de promover a justiça social, representa um ponto de inflexão do próprio valor da igualdade.

(Gilmar Mendes)

(18) Essa conclusão pressupõe, de início, o reconhecimento da dimensão substantiva ou material da igualdade, a mitigar a sua tradicional concepção puramente formal.

(Luiz Fux)

(19) Numa visão pueril e descompromissada, a utilização de critérios étnicos ou raciais para beneficiar certos grupos não soaria compatível com a garantia da igualdade, nem com a vedação ao racismo e à discriminação, insculpidas na Constituição da República.

(Luiz Fux)

(20) Agora, o todo constitucional, sobretudo a sua densa axiologia de não discriminação e de proclamação de igualdade naquele sentido aristotélico e também retomado por Rui Barbosa, toda a política de promoção racial que se dote de proporcionalidade e de razoabilidade deita raízes, repousa no regaço da Constituição brasileira.

(Ayres Brito)

As FNs em análise podem ser assim distribuídas: 


\begin{tabular}{|l|l|}
\hline Convergentes & \multirow{2}{*}{ Foco } \\
\cline { 1 - 1 } O princípio da & \multirow{2}{*}{ igualdade } \\
\cline { 1 - 1 } a clássica concepção liberal de & \\
\cline { 1 - 1 } o direito à & \\
\cline { 1 - 1 } dimensão substantiva ou material da & \\
\cline { 1 - 2 } a garantia da & \\
\cline { 1 - 2 } proclamação de & \\
\hline
\end{tabular}

Nesse grupo, a constituição das FNs apresenta uma diferença formal, na medida em que o nome igualdade está na relação de dependência em relação ao núcleo sintagmático. No entanto, os dois modos de pertinência enunciativa de igualdade observados no $2^{2}$ grupo se mantêm na relação de convergência: situantes e deslocadoras.

Com efeito, em "princípio de igualdade", por exemplo, situa-se a igualdade como um princípio, preservando, portanto, o centro temático ( $X$ igual a $Y$ ) que sustenta o referencial histórico. Temos, nesse caso, uma evidência da pertinência enunciativa situante. 0 mesmo acontece em "a clássica concepção liberal de" e "o direito à". Em todas as ocorrências há a manutenção do referencial histórico de igualdade, uma vez que os convergentes apenas situam o centro temático.

Por sua vez, em "o próprio valor da", "dimensão substantiva ou material da", "a garantia da" e proclamação de", temos convergentes enunciativamente deslocadores. Em "proclamação de igualdade", por exemplo, temos o inverso de um princípio, na medida que há de se produzir dimensão material, garantir e mesmo proclamar a igualdade. Dessa maneira, temos aqui, não o mero situar a igualdade, mas deslocar a sua condição de princípio, colocando-a como objeto de ações (garantir, proclamar, conferir valor, redimensionar). Nesses casos, a constituição das pertinências enun- ciativas desloca o eixo do referencial, de (X igual a $Y$ ) para (ação para $X$ ser igual a $Y$ ).

\section{d) Grupo IV}

Nesse grupo, a FN abriga uma relação de articulação por coordenação com "igualdade", como em:

(21) No que é a igualdade e a igualação, a Constituição brasileira de 1988 produziu, a meu ver, uma grande diferença em relação aos outros textos constitucionais, porque não apenas reforçou o que havia desde a Carta de 1824 - que já falava na igualdade, apesar de termos sido o último povo deste continente a acabar com a escravidão, mas se tinha, ali, a referência ao princípio da igualdade formal -, mas por partir da compreensão de que a igualdade é processo dinâmico, por isso a igualação, porque a igualdade é estática, é garantia daquele que já se igualou. E a igualação é um processo dinâmico de fazer com que aqueles que não adquiriram ainda uma condição de poder ter igualdade de oportunidades para ser igualmente livres, possam vir a adquirir essas condições.

(Carmen Lúcia)

A FN em análise pode ser assim distribuída:

\begin{tabular}{|l|l|}
\hline Foco & Convergente \\
\hline A igualdade & (e) a igualação \\
\hline
\end{tabular}

Ao situar igualdade e _ na mesma FN contrai-se uma razão enunciativa que está acima da mera coordenação de dois substantivos no mesmo sintagma. Com efeito, temos aqui uma equiparação, e, nesse caminho, uma variante do deslocamento do referencial histórico de igualdade, uma vez que coloca "no mesmo lugar" de igualdade a igualação, que é uma ação de igualar 
(tornar $X$ igual a $Y$ ). Dessa maneira, o deslocamento do referencial histórico de inerência ( $Y$ igual a $Y$ ) sustenta a direção da pertinência enunciativa, invocando algo a se fazer para que se atinja a concepção de igualdade.

A observação do funcionamento das FNs nos quatro grupos nos indica que o sentido de igualdade é histórico, não é natural e absoluto. Isso é revelado pelas articulações de convergência com a palavra igualdade. Uma análise dessas FNs do ponto de vista da semântica levou-nos ao processo enunciativo de constituição dessas unidades nominais, isto é, às razões enunciativas do dizer. $\mathrm{O}$ conceito de formação nominal abriga, portanto, as razões enunciativas do acontecimento que levou à constituição das unidades nominais.

Um esboço dessa análise indica que igualdade comparece nas FNs segundo um referencial histórico de algo concebido "em si mesmo" ( $X$ igual a $Y$ ), e recebe determinações de sentido advindas de novas pertinências sociais (igualdade material, por exemplo). Dessa maneira, tendo em vista que o sentido de igualdade é determinado historicamente, existem movimentos e ações que promovem essas variações na igualdade. Esses movimentos e ações que forjam a(s) igualdade(s), incluindo-se aí a implementação de cotas em processos seletivos, encontram sua pertinência enunciativa na "igualização" de "diferentes" socialmente (pela raça, por exemplo).

Assim, a igualdade situada na pertinência enunciativa é uma proposição decretada em lei. Em outros termos, ela é o resultado de $A$ deve ser igual a $B$, sendo que "A" e "B" são os indivíduos e grupos diferentes socialmente; sendo ainda "deve ser igual" o discurso da imposição legal para criar a igualdade, isto é, a proposição que faz $A$ ser igual a $B$. Sendo assim, na verdade, a palavra "igualdade", ao invés de designar uma realidade, produz a condensação de um efeito de realidade no Brasil.

Abordamos a constituição material, sintática, da enunciação de igualdade nos textos do judiciário, através da análise de formações nominais. Observamos que se instala um paradoxo na concepção de igualdade, como aparece na Constituição, por um lado, e como ela aparece nas práticas enunciativas do cotidiano.

A Constituição fundamenta a igualdade na condição de um referencial histórico de "ideia". No entanto, falta um fundamento de "ideal". Diferentemente da concepção que funda a Revolução Francesa, constituído como ideal constitutivo dos valores da nação. No caso do Brasil, a fundamentação em ideia, e não em ideal, leva à necessidade de uma igualação, ou igualização, que seria justamente uma ação no sentido de tornar igual. A igualação envolve, portanto, os movimentos no sentido de fazer a ideia de igualdade, pregada pela Constituição, funcionar. As cotas seriam justamente os instrumentos de igualação, no sentido de fazer funcionar a ideia de igualdade.

Do ponto de vista da materialidade linguística, as formações nominais abrigam os lugares sintáticos em que a ideia de igualdade, como fator de referencial histórico sustentador do nome, recebe as convergências que projetam a pertinência enunciativa da igualação, isto é, da ideia de igualdade presente na Constituição para as ações de elaboração dessa igualdade nas práticas cotidianas.

A análise das formações nominais demonstra o paradoxo da igualdade no Brasil: ao mesmo tempo em que ela se ancora na ideia de que todos os brasileiros são iguais $(a=b)$, há que se fazer pertinente essa igualdade, na ação de constitui-la. Portanto, os brasileiros não são iguais $(a \neq b)$, e será preciso constituir, na adoção das cotas, a igualdade pelo exercício imposto pela lei.

Em suma, a análise da enunciação, pelas formações nominais, nos autoriza a sustentar a concepção segundo a qual a Constituição se inspirou no "ideal" europeu da igualdade, mas o que nela se configurou foi a simples "ideia". Nessa direção, as formações nominais denunciam o acontecimento da produção do sentido de igualdade, que se situa entre o referencial histórico da ideia de igualdade que sustenta o substantivo e a pertinência 
dessa ideia no Brasil, constituída pela igualação/igualização demonstrada nas convergências que determinam o substantivo. Pela pertinência enunciativa, podemos perguntar: o que é igualdade para nós, brasileiros? A resposta passaria pela saída da ideia para a ação, já que a igualdade não está sustentada em um ideal, isto é, não aflora socialmente.

\section{Considerações finais}

Se a igualdade não é natural, pois seria algo igual a si mesmo, sem pertinência, a questão é considerar a igualdade como uma proposição, isto é, propõe-se que $A$ seja igual a $B$, sendo que $A$ e $B$ não são naturalmente iguais. E aí, há que se perguntar o que fundamenta a relação entre $A$ e $B$ na formação nominal. A nossa resposta passa pelo referencial que sustenta essa proposição, de um lado, e pela pertinência enunciativa, de outro, isto é, por que, para que se propõe a igualdade.

As articulações da materialidade linguística nas construções nominais, envolvendo a palavra "igualdade" com os seus determinantes, apresentam como fundamento e razão enunciativa as articulações entre os referenciais históricos da relação entre $A$ e $B$ e as pertinências que essa articulação contraem no presente do enunciar. Isso caracteriza o acontecimento enunciativo. Ele é acontecimento porque não é natural, é uma proposição de interesse, de direcionamento. Por isso, é argumentativo na nossa perspectiva. A argumentação está no direcionamento de dois pontos que não partem da igualdade em si e são propostos como iguais.

A análise tomou em consideração o caráter da formação e não do sintagma formado, isto é, o processo de caráter enunciativo que o formou. Essa perspectiva de análise semântica nos permitiu conceber a significação de igualdade no contexto brasileiro atual como uma proposição de igualdade, tendo em vista que está determinado por um dizer que igualiza. Dessa maneira, igualdade é uma igualização no enunciar.

\section{Referências}

ACHARD, P. Memória e produção discursiva do sentido. In: ACHARD, P. et al. Papel da memória. Campinas: Pontes, 1999. p. 11-21.

BRASIL. Supremo Tribunal Federal. ADPF n. 186 SL/DF. Suspenção Liminar na Arguição de Descumprimento de Preceito Fundamental. Relator: Min. Ricardo Lewandowski. 20 de julho de 2009. Disponível em: <http://www.stf.jus.br/portal/geral/verPdfPaginado. asp?id=400108\&tipo=TP\&descricao=ADPF\%2F186> . Acesso em: fev. 2016.

BRASIL. Supremo Tribunal Federal. Acórdão da Arguição de Descumprimento de Preceito Fundamental. Brasília, 2014. 233 p. Disponível em: <http://redir.stf.djus.br/ paginadorpub/paginador.jsp?docTP=TP\&docID=6984693>. Acesso em: jan. 2016.

DIAS, L. F. Formações nominais designativas da língua do Brasil: uma abordagem enunciativa. Letras, Santa Maria, v. 23, n. 46, p. 11-22. jan./jun. 2013.

DIAS, L. F. Língua e nacionalidade no Brasil na primeira metade do século XX. Polifonia (UFMT), Cuiabá, v. 22, p. 11-31, 2015.

DIAS, L. F. Nomes de cidades de Mato Grosso: uma abordagem enunciativa, In: KARIM T. M.; DI RENZO, A. M.; BRESSANIN, J. A.; KARIM, J. M. (Org.). Atlas dos nomes que dizem histórias das cidades brasileiras: um estudo semântico-enunciativo do Mato Grosso (Fase I). Campinas: Pontes, 2016. p. 33-49.

DIAS, L. F.; ZATTAR, N. O funcionamento do vocativo: uma abordagem da enunciação. Domínios de lingu@gem. Uberlândia, v. 11, n. 4, 2017. (no prelo)

FOUCAULT, M. A arqueologia do saber. Rio de Janeiro: Forense Universitária, 1986.

FREGE, G. Sobre o sentido e a referência. In: FREGE, G. Lógica e filosofia da linguagem. São Paulo: Cultrix/Ed. da USP, 1978. p. 59-86.

GUIMARÃES, E. Os limites do sentido. Campinas: Pontes, 1995.

GUIMARÃES, E. Semântica do acontecimento. Campinas: Pontes, 2002.

PÊCHEUX, M. [1982] Lecture et mémoire: projet de recherche. In: MALDIDIER, D. L'inquiétude du discours: textes de Michel Pêcheux. Paris: Éditions des Cendres, 1990. p. 285-293.

PÊCHEUX, M. [1983] Papel da memória. ACHARD, P. et al. Papel da memória. Campinas: Pontes, 1999. p. 49-57.

Recebido em: 05/10/17

Aprovado em: 15/12/17 